"El Cuarto Pilar de la Revolución": del internacionalismo proletario a la solidaridad internacional, las transformaciones discursivas del Partido Revolucionario de los Trabajadores en el exilio Leandro Inchauspe páginas / año 12 - n² 29 Mayo-Agosto / ISSN 1851-992X/ 2020 http://revistapaginas.unr.edu.ar/index.php/RevPaginas

\title{
"El Cuarto Pilar de la Revolución": del internacionalismo proletario a la solidaridad internacional, las transformaciones discursivas del Partido Revolucionario de los Trabajadores en el exilio
}

\author{
The Fourth Pillar of the Revolution: from proletarian internationalism \\ to international solidarity, the discursive transformations of the \\ Revolutionary Workers Party in exile
}

\author{
Leandro Inchauspe \\ Escuela de Historia; \\ Facultad de Filosofía y Humanidades; \\ Centro de Estudios Avanzados, Facultad de Ciencias Sociales; \\ Universidad Nacional de Córdoba (Argentina)
}

\begin{abstract}
Resumen
Desde su formación el PRT incluyó la perspectiva del "internacionalismo proletario" reconfigurado a partir de la experiencia vietnamita: la creación del ERP respondía, tras el Cordobazo, al inicio de la "guerra civil revolucionaria" (contra la burguesía y el ejército opresor) que pasaría a "guerra civil antiimperialista" (también contra un enemigo invasor). Esta perspectiva definía a la solidaridad internacional como el "Cuarto Pilar de la Revolución", junto al partido, ejército y frente de liberación. A partir de la intensificación del accionar represivo luego del golpe, con el exilio de la militancia sobreviviente, el Cuarto Pilar adquirió más relevancia, dentro de la limitada posibilidad de su accionar. En este artículo analizaremos las definiciones teóricas con que el PRT en el exilio intentó adecuar sus estrategias al nuevo contexto represivo. Tomando aspectos del concepto de "redes transnacionales de defensa", a manera de hipótesis, sostenemos que estas definiciones articularon internacionalismo clásico (que suponía acercamiento al Movimiento Comunista Internacional liderado por la URSS, aun rompiendo definitivamente con su origen trotskista) con la experiencia vietnamita (que hizo un estratégico uso de la denuncia de la represión en foros internacionales y dentro del llamado "movimiento por la Paz Mundial" en países capitalistas).
\end{abstract}

Palabras Clave

PRT-ERP; Internacionalismo; Exilio; Solidaridad Internacional

\footnotetext{
Abstract

From its formation the PRT included the perspective of "proletarian internationalism" reconfigured from the Vietnamese experience: the creation of the ERP responded, after Cordobazo, at the beginning of the "revolutionary civil war" (against the bourgeoisie and the oppressing army) that it would go on to "anti-imperialist civil war" (also against an invading enemy). This perspective defined international solidarity as the "Fourth Pillar of

Esta obra está sujeta a la Licencia Reconocimiento-NoComercial-CompartirIgual 4.0 Internacional de Creative Commons. http://creativecommons.org/licenses/by-nc-sa/4.0/

(cc) BY-NC-SA
} 


\section{Leandro Inchauspe}

the Revolution", together with the party, army and liberation front. From the intensification of the repressive action after the coup, with the exile of the surviving militancy, the Fourth Pillar acquired more relevance, within the limited possibility of its action. In this article we will analyse the theoretical definitions with which the PRT in exile tried to adapt its strategies to the new repressive context. Taking aspects of the concept of "transnational networks of defence", as a hypothesis, we maintain that these definitions articulated classic internationalism (which supposed an approach to the International Communist Movement led by the USSR, even definitively breaking with its Trotskyist origin) with the Vietnamese experience (which made a strategic use of the denunciation of repression in international forums and within the so-called "movement for World Peace" in capitalist countries).

\section{Keywords}

PRT-ERP; Internationalism; Exile; International Solidarity

\section{Introducción}

El PRT se conformó por la fusión del grupo trotskista "Palabra Obrera" (PO) con el "Frente Revolucionario Indoamericano Popular" (FRIP), que reivindicaba los postulados del APRA peruano y de Mariátegui, sosteniendo una perspectiva latinoamericana del proceso revolucionario: "ha quedado demostrado que las luchas aisladas en cada país son fácilmente cercadas por el imperialismo"1. Por su parte, PO aportó la concepción del internacionalismo proletario, cuyo abandono por el comunismo soviético era una clásica crítica trotskista. Hacia 1962 editaba un "boletín periódico... semanal en el cual resumiremos las noticias internacionales" (Boletín Interno Internacional $n^{\circ} 1$, circa 1964) ${ }^{2}$ que da cuenta sucintamente de luchas políticas y sindicales en diferentes países. Si bien no profundizaremos, podemos afirmar que el latinoamericanismo del FRIP fue fundamentalmente principista, en tanto el internacionalismo de PO se expresó, como sostiene Mangiantini, en forma "teórica ... y, por otro práctica" (2018:67) ${ }^{3}$ : participación de delegados "fraternales" de "partidos hermanos" en congresos partidarios, solidaridad ante represión sobre militantes trotskistas en el extranjero, también participación militar en Perú y formación en Cuba. Esta atención a la dimensión internacional, particularmente latinoamericana, constituirá una marca de origen de la organización.

\footnotetext{
1 "Lucha de los Pueblos Indoamericanos - Antiimperialismo e Integración", Norte Argentino, 1963, Secretaría Ideológica $\quad$ FRIP, en https://elsudamericano.wordpress.com/2013/09/12/lucha-de-los-pueblos-indoamericanosantiimperialismo-e-integracion-frip-1963/

2 Fundación Pluma, Primer período: del GOM al PST inclusive, Documentos entre 1959 y 1968, recuperado en http://fundacionpluma.info:8080/xmlui/handle/123456789/1557

${ }^{3}$ Si bien Mangiantini analiza la etapa de la unificación FRIP - PO y la trayectoria posterior del sector que se mantuvo en el trotskismo (PRT "La Verdad", PST) señala estas características tanto en la década de 1940 (participación en el Segundo Congreso de la IV Internacional) como en dictadura, en la que los vínculos internacionalistas sirvieron para el exilio y la denuncia (2018: 59-67). Sobre esta etapa: Mangiantini, M (2017) "Redes militantes y acciones en el exilio. La política internacionalista del Partido Socialista de los Trabajadores (1976-1982)”, Estudios, núm. 38, pp. 87-104.
} 


\title{
"El Cuarto Pilar de la Revolución": del internacionalismo proletario a la solidaridad internacional, las transformaciones discursivas del Partido Revolucionario de los Trabajadores en el exilio
}

Los primeros años: del trotskismo al guevarismo

Como hemos señalado (2018) en las batallas ideológicas perretianas se recurrió a la tradición teórica marxista y a las experiencias revolucionarias, en las que lo internacional era central. Analizando la situación nacional desde ese bagaje, la organización consideró que el Cordobazo significaba la extensión de la "Guerra Revolucionaria" que ya se había iniciado en Tucumán4. Dicha guerra "tendrá consignas antiimperialistas, dado el carácter de semicolonia de nuestro país ... se irá transformando en guerra civil antiimperialista ... porque lucharemos contra la burguesía y contra un enemigo invasor" (Resoluciones del IV Congreso, De Santis, 2000: 34). Su desarrollo trazaba las políticas de alianzas:

\begin{abstract}
"En ese momento [guerra civil antiimperialista, contra un enemigo invasor] nuestras consignas [deberán sumar] a sectores de las capas superiores de la pequeña burguesía y mediana burguesía e incluso sectores de las fuerzas represivas ... contra la burguesía y el imperialismo" (2000: 34).
\end{abstract}

La experiencia revolucionaria que la organización identificaba como más próxima no era la insurrección popular estilo Comuna de París de 1871 (lo que lo diferenciaba de las corrientes "espontaneístas"), ni la "la toma del Palacio de Invierno" (lo diferenciaba de las concepciones "etapistas" del comunismo soviético), ni la "guerra popular prolongada" del "campo a las ciudades" (lo diferenciaba del maoísmo y del foquismo guevarista) si no el modelo vietnamita: a la etapa de guerra civil revolucionaria le seguiría una intervención estadounidense, consecuentemente una guerra patriótica sumando a sectores pequeño y mediano burgueses e incluso de las fuerzas armadas. Este imaginario es recurrente, marcado por una fuerte atención a lo internacional.

En las "Resoluciones" del IV y V congresos partidarios - febrero de 1968 y Julio de 1970, respectivamente - documentos claves de la organización, en contextos decisivos; la discusión se centraba en las estrategias y tácticas apropiadas, el debate se dirimía a partir de la teoría marxista, la situación nacional, latinoamericana (a pesar de los fracasos de la "teoría del foco guerrillero" propuesta por el "Che" Guevara, el influjo cubano mantenía el alza continental de las izquierdas) y mundial (con la referencia clave de Vietnam y las luchas anticoloniales, también en auge). En el primer caso, en el marco de disputas de facciones respecto a la "corrección" del inicio de la lucha armada, entre "santuchistas" (que lo apoyaban) y "morenistas"

\footnotetext{
4 Recordemos que el FRIP se desarrolló en Tucumán, donde la resistencia sindical al cierre de ingenios azucareros incluyó sabotajes, enfrentamientos y otros episodios de violencia que fue tomado como indicador de la "disposición" de las masas hacia la "guerra revolucionaria". El Cordobazo sería leído en clave de su nacionalización, con el plus de ser protagonizado por el sujeto histórico privilegiado del marxismo: el proletariado industrial.
} 


\section{Leandro Inchauspe}

(que consideraban debía retrasarse) 5 ; se abordaba la situación interna del partido; la inserción en los "frentes de masas"; las características de la "guerra revolucionaria"; las decisiones políticas y organizativas y extensas consideraciones sobre el "movimiento revolucionario internacional". Por otra parte, si bien ambos documentos son firmados con seudónimos, dada la condición clandestina de la organización, la tradición oral ubica en ambos a Santucho, bajo diversos alias. Es decir, son textos de quien en esos años iría construyendo una posición de liderazgo que se consolidó indiscutiblemente en los 70', cuando llegaría a “Secretario General del PRT y Comandante del ERP.

En la Declaración, bajo el título "Relaciones entre la Revolución Mundial, Continental y Regional", se afirmaba que "Desde su nacimiento, el marxismo tomo en cuenta ... el carácter mundial de la revolución" (Resoluciones del IV Congreso, De Santis, 2004: 181). La autoridad de los 'padres fundadores' de la tradición revolucionaria era invocada: "Marx, Engels, Lenin y Trotsky consideraban indispensable una organización revolucionaria internacional ... para impulsar la revolución mundial" (2004: 182). En su presente, caracterizado por el "imperialismo yanqui ... gendarme de la contrarrevolución mundial” (2004: 182), solo habían adecuado sus estrategias "la dirección castrista" y el "FLN de Vietnam". Ellos, junto a la IV Internacional, debían liderar una nueva "Organización Internacional" para la revolución mundial, cuya consigna era "la creación del segundo o tercer Vietnam del mundo" (2004: 188).

Como señalamos, si bien el IV Congreso se saldó con la expulsión de la fracción morenista - que continuaría un tiempo con la denominación "PRT - La Verdad", luego Partido Socialista de los Trabajadores - y la adopción de la lucha armada; numerosas dificultades y debates demorarían su inicio y llevarían al V Congreso, con lo internacional nuevamente ocupando la atención. En una "minuta" (en la jerga militante, texto de breve o mediana extensión que desarrolla una posición política, muchas veces en polémica con otras) firmada por Santucho, se alude nuevamente a la centralidad del internacionalismo: "Marx dijo que la revolución socialista es nacional por su forma e internacional por su contenido y que la lucha del proletariado ... es una lucha internacional" (Minuta sobre Internacional, De Santis 2004: 330). Concretando esa perspectiva, se construyó la "Asociación Internacional de Trabajadores" y las sucesivas organizaciones hasta la "Segunda Internacional" de Engels. Esta línea habría sido seguida por Lenin y los bolcheviques rusos con la fundación de la "Tercera Internacional" en 1918. En la perspectiva perretiana, todavía fuertemente trotskista, la Internacional, hasta la muerte de Lenin, "centralizó prácticamente la lucha revolucionaria del proletariado internacional" (2004: 331) hasta que el estalinismo "degeneró la Internacional, subordinándola a los intereses nacionales de la Unión Soviética”.

\footnotetext{
${ }^{5}$ La confluencia de una corriente indoamericanista y otra trotskista se expresó en los liderazgos de Mario Roberto Santucho, luego principal dirigente del PRT-ERP, y Nahuel Moreno, quien continuaría en la línea trotskista luego de la ruptura.
} 


\title{
"El Cuarto Pilar de la Revolución": del internacionalismo proletario a la solidaridad internacional, las transformaciones discursivas del Partido Revolucionario de los Trabajadores en el exilio
}

Cuando el análisis se acercaba al presente, nuevamente se aludía al aporte cubano "internacionalismo práctico" denomina a la estrategia guevarista de la Tricontinental y la OLAS - y de la lucha vietnamita -"lucha revolucionaria con contenido y forma internacional"- y elaboraba un mapeo de las fuerzas internacionales. En la "extrema derecha" situaba "el revisionismo acaudillado por ... la Unión Soviética ... los partidos comunistas de los Estados Obreros Europeos (con la sola excepción de Albania) y los partidos comunistas línea Moscú" (2004: 333). La caracterización era lapidaria: "ha abandonado la lucha revolucionaria contra el capitalismo y el imperialismo". Por otro lado, se encuentran "el Partido Comunista chino, el Partido Comunista cubano, el Partido del Trabajo albanés, el Partido de los Trabajadores de Vietnam, el Partido Comunista coreano ... vanguardia real del movimiento revolucionario mundial" (2004: 333-334). Esta debería ser la base de una nueva Internacional, que no se concretaba por "la expresa posición" de los partidos chino, vietnamita, coreano y albanés, que la consideraban perjudicial. En tercer lugar, se encontraba el "movimiento trotskysta (sic) internacional y ... otras corrientes revolucionarias internacionalistas que ... luchan con las armas en la mano y ... comienzan a rescatar la bandera internacionalista" (2004: 334) entre las cuales situaba al PRT. En las conclusiones, se explicitaba un intento de conciliar la tradición trotskista con el más reciente influjo guevarista:

\begin{abstract}
"Ratificamos nuestra adhesión [a la IV Internacional] para luchar porque ella se oriente a la formación del nuevo partido revolucionario internacional basado en los partidos chino, cubano, coreano, vietnamita y albanés y ... las corrientes no trotskystas (sic) de todo el mundo, especialmente con las organizaciones combatientes de América Latina" (2004: 337).
\end{abstract}

En cuanto a prácticas concretas, la articulación internacional que conformó el PRTERP sería la "Junta de Coordinación Revolucionaria (JCR)", creada a comienzos de 1973, junto al MIR chileno, los Tupamaros uruguayos y el ELN boliviano. La JCR editó la revista "Che Guevara"; llevó adelante una "escuela de cuadros" para la formación política y militar, que prolongará su accionar incluso durante el exilio. Instaló una fábrica clandestina de armas en Argentina (hasta ser desbaratada en momentos de intensificación de la represión), coordinó actividades y compartió recursos económicos obtenidos por sus miembros (principalmente por la operatividad del PRT-ERP).

No nos detendremos en extenso en esta experiencia de "internacionalismo armado"6 según la expresión de Sujatt (2016) pero daremos cuenta de algunas de las

\footnotetext{
${ }^{6}$ La propia JCR podría ser pensada como red transnacional, en tanto articulaba exiliados/as de las dictaduras de Seguridad Nacional que se estaban instalando. No parece apropiado denominar "de defensa" en tanto se trata de una etapa en la que las organizaciones mantenían capacidad operativa; aun cuando sufrían fuertes golpes. Marchesi también caracteriza a la JCR en términos de red, y demuestra una interesante paradoja: si bien "ayudó a posponer las derrotas y a amplificar los planes
} 


\section{Leandro Inchauspe}

posiciones de su documento fundacional, "A los pueblos de América Latina", para rastrear las continuidades con aquellas posiciones iniciales.

Un rasgo notable es la constante referencia al guevarismo. Es evocado en el nombre mismo, tomado de la propuesta del Che en su 'Mensaje a la Tricontinental'. Su autoridad es invocada en el tercer párrafo: "Este importante paso [la creación de la JCR] es la concreción de una de las principales ideas del Comandante Che Guevara, héroe, símbolo y precursor de la revolución socialista continental" ("A los pueblos de América Latina”, De Santis, 2000: 367). A lo largo de sus páginas se apela no ya a la tradición revolucionaria clásica (ni siquiera a la Revolución Bolchevique) sino a las luchas latinoamericanas: las guerras por la independencia del siglo XIX, el anarquismo, socialismo y comunismo de principios del XX, Sandino en Nicaragua, las intervenciones del imperialismo yanqui, el reflujo de los años pre y post Segunda Guerra Mundial, hasta llegar a la Revolución Cubana. Una sola excepción rompía la continuidad latinoamericana, Vietnam. De hecho, es el "Guerrillero Heroico" quien enlaza ambas experiencias: "como lo vislumbrara el Comandante Guevara, [es necesario] desarrollar una cruenta y prolongada guerra revolucionaria que hará del continente latinoamericano el segundo o tercer Vietnam del mundo" (2000: 372).

Otro matiz en esta versión más guevarista del internacionalismo, casi latinoamericanismo, que el PRT-ERP transitaba en el marco de la JCR, respecto a la más trotskista, refiere a las corrientes políticas contra las que se disputaba. En efecto, más aún que el stalinismo y el revisionismo, se trataba del "nacionalismo burgués" y el "reformismo". El primero, es definido en términos que, para el caso argentino, parecían aludir a la caracterización que el PRT realizaba del peronismo:

"El nacionalismo burgués es una corriente apadrinada por el imperialismo ... variante demagógica para distraer y desviar la lucha de los pueblos... mediante el truco de presentarse como bomberos del incendio revolucionario, con influencia popular y capacidad de negociación ante la movilización de las masas ... esgrimen un antiimperialismo verbal e intentan confundir a las masas con su tesis nacionalista preferida: la tercera posición" (2000: 371) .

Por su parte, el reformismo es definido con una fisonomía coincidente con la que Santucho refería a Moreno:

"corriente que anida en el propio seno del pueblo trabajador, reflejando el temor al enfrentamiento de sectores pequeño burgueses y de la aristocracia obrera ... Se caracteriza por rechazar cerradamente en los hechos la justa y

militares de las organizaciones" (2009:66) al mismo tiempo expresó su aislamiento respecto a las luchas locales, aumentando su debilidad. Para ampliar: Sandoval, M. (2016). "Un fruto del exilio: La Escuela Internacional de Cuadros de la JCR (Junta de Coordinación Revolucionaria)" Recuperado en http://www.memoria.fahce.unlp.edu.ar/trab_eventos/ev.9330/ev.9330.pdf. Sandoval, M. (2016) "La Junta de Coordinación Revolucionaria (JCR): el Internacionalismo Proletario del Cono Sur, 19721977", Tesis para el grado de Maestro en Historia Internacional, CIDE, México. Recuperado en http://www.cedema.org/uploads/Sandoval_Mercado-2016.pdf 


\title{
"El Cuarto Pilar de la Revolución": del internacionalismo proletario a la solidaridad internacional, las transformaciones discursivas del Partido Revolucionario de los Trabajadores en el exilio
}

\author{
necesaria violencia revolucionaria ... difunde entre las masas nocivas ideas \\ pacifistas y liberales, ... exageran la importancia de la legalidad y el \\ parlamentarismo" (2000: 371).
}

Frente a ambos "se alza el polo armado" como única alternativa, con lo que el documento termina con una muy clara consigna "Pueblo Latinoamericano: a las armas" (2010: 374).

\section{El desafío de construir el Cuarto Pilar: el PRT en el exilio}

Como sabemos, la represión intensificada con el golpe significó para las organizaciones armadas una durísima derrota: la Regional Córdoba del PRT-ERP, por caso, fue totalmente destruida entre abril de 1976 y mayo de 1977. Obturadas casi por completo las posibilidades en el país, las organizaciones adoptaron el camino del exilio. Cabe entonces la pregunta respecto a los cambios discursivos a partir de esta situación. Igualmente, la aplicación parcial de la categoría de "redes transnacionales de defensa" (en adelante, RTD) de Keck y Sikkink (1999) nos abre una fecunda vía de aproximación, tomando algunos de sus aspectos ${ }^{7}$. Las definen como "redes ... formadas por activistas [en torno a] valores o principios ... En temas como ... los derechos humanos, ponen recursos internacionales a disposición ... de las luchas sociales". Ellas permiten la posibilidad de "presionar e influir en ...

\footnotetext{
7 Somos conscientes que la aplicación de la categoría RTD al PRT durante el exilio puede resultar compleja. Principalmente se ha aplicado a la dimensión transnacional del Movimiento por los DDHH: D’Antonio, D (2018) “Redes de denuncias políticas y jurídicas por violaciones a los derechos humanos en el plano internacional: el rol de las Madres de Plaza de Mayo (Argentina, 1976-1983)", Travesía, Vol. 20, № 2, pp. 15-44. Garza Placencia, J (2017). “Actores y redes del movimiento por los derechos humanos en América Latina”, Boletín de Antropología, vol. 32, N. 5 53 pp. 158 - 179. Laino Sanchis, F (2020) "Salir al mundo en tiempos de dictadura: Abuelas de Plaza de Mayo y las redes transnacionales de derechos humanos (1977-1983)", Quinto Sol, vol. 24, no1, pp. 1-22. Ya canónica es la compilación de Jelin, E (2003) Más allá de la nación: las escalas múltiples de los movimientos sociales, Libros del Zorzal, Buenos Aires. Enfatizando en el exilio: Ayala, M (2017) "La experiencia del Comité Venezolano de Solidaridad con el pueblo argentino (Caracas, Mérida, 1976-1983)", Opción, vol. 33, núm. 83, pp. 12-136 y (2014) "La formación de comités y redes de lucha contra la dictadura militar de los exiliados argentinos en Venezuela: interacciones locales, regionales y transnacionales (1976-1981)", e-l@tina, vol. 12, núm. 46, pp. 1-21. Lolicato, A (2011) "Mantenerse en contacto: medios de comunicación y movilidad humana en el activismo político transnacional. El caso de los colectivos de argentinos en Barcelona y Roma", Arxiu d'Etnografia de Catalunya, n.o 11, pp. 95-114 y muchos otros sobre distintos destinos de exilio. Las redes vinculadas a cultos religiosos han sido trabajadas por Catoggio, M (2016) "Política contra el Estado autoritario, religión y derechos humanos. La impronta regional de un activismo transnacional", Papeles de Trabajo, 10(17), pp. 184207. La dimensión sindical ha sido trabajada en Gordillo, M (2017) "Activismo sindical transnacional en el Cono Sur: Algunas experiencias", Clepsidra, Vol 4, Núm 7, pp. 68-83, desde una categoría similar: "activismo transnacional" de Tarrow. Una menor atención ha recibido cuando se articulan en base a partidos políticos: Pedrosa, F (2013) "Redes trasnacionales y partidos políticos. La Internacional Socialista en América Latina (1951-1991)", Iberoamericana, Año 13, No. 49, pp. 25-46. Más ligado a nuestro trabajo: González Tizón, R (2018) "La denuncia de la represión clandestina durante la dictadura en Argentina: el caso de los sobrevivientes de Vanguardia Comunista (1978-1983)", Izquierdas (43), pp. 23-51. Desde esta particularidad de RTD "partidarias" nos situamos.
} 


\section{Leandro Inchauspe}

gobiernos muchos más poderosos" (1999: 91). Con el objeto de ampliar sus públicos, atraer la atención, producir acciones e instalarse en "jurisdicciones institucionales favorables", las RTD realizan acciones claves para nuestro análisis: "enmarcar ... esfuerzos estratégicos conscientes realizados por grupos de personas para conformar visiones compartidas del mundo y de sí mismos que legitimen y motiven las iniciativas colectivas" (Mc Adam, Mc Carthy y Zald, en Keck y Sikkink, 1999: 91). En esta tarea de enmarque podemos comprender las derivas del posicionamiento internacional de la organización en los años dictatoriales. Avanzando en la descripción del enmarque, Keck y Sikkink señalan que "los grupos de activistas enmarcan los temas de manera sencilla, en términos de bien y mal, porque su finalidad es persuadir" (1999: 104, itálicas en el original) ${ }^{8}$.

Según Carnovale el "repliegue" del PRT, que se concretó principalmente en exilio hacia finales de 1976, se inició con la perspectiva de un corto período de preservación y entrenamiento de los cuadros partidarios y militares, en la convicción de un pronto retorno a la lucha cuando se iniciara el "nuevo auge de masas" previsto en torno a un año después del golpe. Las analogías, en las lecturas que Carnovale realiza de las memorias militantes de Gorriarán Merlo, uno de los máximos dirigentes luego de las caídas de las conducciones nacionales, eran nuevamente cubanas: como Fidel luego del fracaso en el Moncada, la situación que enfrentaba la organización se asimilaba con el exilio cubano en México como paso previo al retorno triunfal (Gorriarán Merlo en Carnovale, 2014: 4). Por su parte Mattini, el otro líder partidario luego de la desaparición y muerte de Santucho y demás dirigentes, coincidía con las tareas de preparación política militar para el pronto retorno y le agregaba otra línea sobre la que nos explayaremos: "la labor de solidaridad internacional denunciando la situación de la población de Argentina" (Mattini en Carnovale, 2014:5) ${ }^{9}$.

El 'cuarto pilar' adquiría entonces mayor centralidad, por la virtual desarticulación de las posibilidades de accionar para el partido, el ejército y el frente de liberación.

\footnotetext{
${ }^{8}$ La discursividad de la izquierda revolucionaria latinoamericana durante el exilio y las transiciones a la democracia ha sido tematizada en términos de 'abandono' de 'la revolución' y pasaje hacia los DDHH, con un papel clave de las RTD. En un trabajo que sentaría las bases de esta perspectiva, Jelin sostiene: "es a partir de los golpes militares del Cono Sur que las redes internacionales de activistas y organizaciones ligadas a los derechos humanos se incorporan como actores significativos en la protesta contra la represión y el terrorismo de estado (Keck y Sikkink 1998) ... lo que ocurrió en ese período fue la incorporación del marco de los derechos humanos en la lucha anti-dictatorial. Antes ... interpretadas en términos de lucha de clases o de revoluciones nacionales. La incorporación de la clave "violaciones a los derechos humanos" fue ... una verdadera revolución paradigmática" (2003:5). Sin desconocer esta tesis, en particular para el discurso de la comunidad intelectual de la izquierda revolucionaria, creemos que en el caso que nos ocupa no se aplica. Como intentaremos demostrar, se trataría de esfuerzos de enmarque más que de abandono de una discursividad y pasaje hacia otra.

${ }^{9}$ Sin suponer una continuidad lineal, del sector Mattini surgiría en 80' el "Movimiento Democrático Popular Antiimperialista-MoDePA", que según Carnovale abandona la lucha armada y adopta una concepción de 'revolución por etapas' al estilo de los partidos comunistas ortodoxos, con el matiz de sostener el carácter 'popular' (y no burgués) de la forma adecuada para la Argentina. La línea de Gorriarán, luego de combatir en Nicaragua, formará parte del heterogéneo 'Movimiento Todos por la Patria - MTP', cuya fallida incursión en La Tablada en 1989 ha sido considerado por diversos/as autores/as, Carnovale incluida, como la última acción de la guerrilla setentista en nuestro país.
} 


\section{"El Cuarto Pilar de la Revolución": del internacionalismo proletario a la solidaridad internacional, las transformaciones discursivas del Partido Revolucionario de los Trabajadores en el exilio}

Para Carnovale esta tarea suponía "la conformación de organismos de 'solidaridad con el pueblo argentino', y el establecimiento de contactos y vínculos formales con distintas fuerzas" (2014: 5). Sin embargo, las denuncias sobre las violaciones a los Derechos Humanos (en adelante, DDHH) por parte de la dictadura argentina en los foros internacionales, pronto encontraría "el bloqueo de la URSS y del campo socialista en general" (2014: 7). Casola (2012) ha señalado los votos negativos de la diplomacia soviética, desde 1977 a 1980, contra intentos de condenas de la ONU por las violaciones de los DDHH de la dictadura. Paradójicamente, al mismo tiempo el partido en el exilio completaba un profundo viraje en sus posiciones internacionales, desde el trotskismo inicial, con la etapa guevarista en el medio, hacia "el alineamiento con la URSS y el campo socialista" (2014:9), uno de los elementos que precipitaron el cisma partidario de febrero de 1979. Pensada bajo el prisma de las RTD de Keck y Sikkink, supone un fracaso en el aspecto referido al objetivo de presionar e influir en gobiernos más poderosos: hasta el final de la dictadura, la URSS ${ }^{10}$ mantendrá la posición de no condenar al gobierno argentino por violaciones a los DDHH.

Pero el factor determinante de la ruptura entre la línea orientada hacia el "eurocomunismo" de Mattini (que se dedicará a las denuncias internacionales y la formación política de los cuadros en Europa, principalmente) y la que mantendría la lucha armada de Gorriarán Merlo (que pronto se incorporaría a la guerrilla sandinista en Nicaragua) no se encuentra tanto en este aspecto de los reposicionamientos políticos internacionales. Si bien no indagaremos en la ruptura (que, por cierto, no era ajena a la corta tradición partidaria: recuérdese la escisión con el grupo morenista en ocasión del IV Congreso y la de dos facciones internas en el V Congreso a las que hemos aludido, así como la del PRT-Fracción Roja y el ERP22 de agosto, hacia 1973; junto a otros desprendimientos menores), resulta de nuestro interés que una de las variables que Carnovale señala como intervinientes en el cisma refiere a otra de las cuestiones de las políticas internacionales en discusión: "latinoamericanismo, por un lado, y comunismo tradicional, por otro" (2014: 20). Realizaremos entonces una lectura de algunos documentos partidarios

\footnotetext{
${ }^{10}$ Esta conflictiva cuestión ha sido objeto de numerosos análisis. Aguila sostiene que "las relaciones establecidas entre la Unión Soviética y la Argentina en los años de la dictadura ... incidió en la actitud del régimen militar respecto del PCA y en la línea política del propio partido hacia el gobierno ... las Fuerzas Armadas visualizaban al PCA como menos amenazante que ... las organizaciones armadas ... Por otra parte, el alineamiento del partido con la Unión Soviética habría contribuido en la decisión ... militar de no ilegalizarlo, evitando de este modo conflictos con la superpotencia ... como ... en Chile ... de Pinochet" (2008: :60). Más adelante señala cómo las relaciones comerciales argentino-soviéticas crecieron, con un pico durante el embargo de cereales impulsado por EE.UU. por la invasión a Afganistán a inicios de los '80. Casola (2012) ha señalado cómo las estrategias internacionales del PCA evitaban una condena internacional a la dictadura. Por su parte, Morello (2012) ha demostrado la influencia de un catolicismo "cívico", moderno, que defendió en EE.UU. la "laicidad, pluralidad" (2012:78) en el cambio de la política de la administración Carter respecto a la dictadura argentina. En este más amplio juego de política internacional y geopolítica, debe entenderse este fracaso de la línea internacional del PRT, desde la perspectiva de las RTD.
} 


\title{
Leandro Inchauspe
}

para visibilizar las torsiones de la línea a la que estamos aludiendo. Aquí, las tareas de enmarque que realizan las RTD, según Keck y Sikkink, resultan esclarecedoras. Hacia 1978 (con la lucha interna ya desatada, pero aún no concretada la ruptura, según Carnovale) se editaba un documento que establecía la línea partidaria para el cuarto pilar de la revolución, titulado justamente "Solidaridad Internacional". Una de las primeras caracterizaciones en que se basa respecto al plano internacional es definirlo en términos de:

\begin{abstract}
"se presentan en el mundo dos campos bien definidos: 1-el imperialistacapitalista con los monopolios norteamericanos a la cabeza 2- el socialista, nutrido por las tres vertientes de la Revolución Mundial: la comunidad socialista, el Movimiento Obrero Internacional y los Movimientos de Liberación Nacional" ("Solidaridad Internacional. Documento aprobado en el III Plenario del Frente Internacional del PRT", 1978: 3) ${ }^{11 .}$
\end{abstract}

Es notable que el partido se ubicara como parte del "campo de la clase obrera" y no con los movimientos de liberación nacional. En la tarea de "enmarque" que estaba realizando, la visión de sí mismo estaba variando respecto a los años previos. Párrafos más adelante se reconocía que la lucha por la democracia se consideraba como una etapa para la mayor conciencia de los intereses de la clase, paso indispensable hacia la lucha por el socialismo - lo que constituía prácticamente un reconocimiento del "etapismo" de los partidos comunistas en línea con Moscú-. Y que en cuanto a las "herramientas estratégicas para el triunfo de la revolución", dadas las características de la etapa, "hace que demos importancia decisiva a la Solidaridad Internacional". En nuestra lectura, el documento coincide con Carnovale en las torsiones de ciertas tradiciones partidarias que se estaban produciendo, que podemos resumir tanto en alejamiento del guevarismo, como en acercamiento al campo socialista y centralidad de las acciones de denuncias internacionales sobre las violaciones a los DDHH ${ }^{12}$. Explicable en términos del enmarque necesario para ampliar sus públicos e instalarse en jurisdicciones institucionales favorables.

En el párrafo siguiente el texto daba cuenta de las complejidades que suponía este acercamiento al campo de la URSS, dada su política de no condenar a la dictadura argentina. Y que, por el contrario, había más receptividad en algunos países capitalistas, incluso en sectores del gobierno y el pueblo de EE. UU13.

\footnotetext{
${ }^{11}$ Recuperado en: http://eltopoblindado.com/opm-marxistas/partido-revolucionario-de-lostrabajadores-prt/prt-exilio/solidaridad-internacional/

12 Como ha señalado Alonso (2017) en los '80 se construyó como hegemónica una narrativa académica sobre el Movimiento de los DDHH que, entre otros efectos de oclusión, desconoció "el papel desempeñado por las izquierdas peronistas y marxistas en la conformación de las agrupaciones de derechos humanos" (2017: 104). Entre las organizaciones partidarias que menciona, incluye al PRT. Contribuimos a tensionar esta tendencia a invisibilizar el papel de los partidos en el campo de los derechos humanos en este trabajo. Y ello justifica la aplicación de algunos aspectos de la categoría de RTD de Keck y Sikkink.

13 Esta particularidad ponía en tensión cierto aspecto de la lógica binaria propia de la Guerra Fría, y no solo afectará al PRT. La particular posición del PCA, que venimos señalando colateralmente,
} 


\title{
"El Cuarto Pilar de la Revolución": del internacionalismo proletario a la solidaridad internacional, las transformaciones discursivas del Partido Revolucionario de los Trabajadores en el exilio
}

En efecto, se señalaba "el hecho objetivo que en los Organismos Internacionales contemos con algún apoyo de las democracias occidentales y aún del gendarme imperialista, mientras el de los países socialistas es escaso" (1978: 3). Esto era explicado en términos de las diferencias entre el "golpe fascista preventivo en Brasil”, el "brutal y sangriento golpe chileno" y la dictadura argentina, que

\begin{abstract}
"se dio contra un gobierno desprestigiado ... de corte pro-imperialista y donde la violencia terrorista del Estado había alcanzado grados desconocidos ... los partidos políticos ... que eran legales a esa fecha no fueron disueltos ... particularmente no lo fue el Partido Comunista ... tampoco se atacó frontalmente a los países socialistas" (1978: 4).
\end{abstract}

En este análisis "ante la falta de agresividad directa, el campo socialista en su conjunto, mantiene relaciones diplomáticas y comerciales con Argentina".

La posición de la administración Carter en EE.UU., por su parte, era explicada en términos de una serie de variables internas - "la necesidad de apoyo interno de sectores democráticos de su propio pueblo" - e internacionales: "el desprestigio internacional de EEUU luego de las aventuras de Vietnam y Chile ... y por la resistencia de las masas latinoamericanas a los regímenes autoritarios” (1978: 5). Ello habría obligado al gobierno estadounidense a una "supuesta defensa de la democracia y los derechos humanos" que probablemente debe haber tensionado fuertemente, más aún frente a la contraria actitud soviética, los posicionamientos del PRT. Como venimos sosteniendo, el "enmarque" como tarea estratégica suponía estas contradicciones.

A pesar de ello, el documento insistía en mencionar la experiencia vietnamita, más aún en un momento de retroceso de las luchas de las masas como el que se desarrollaba, sosteniendo que:

\footnotetext{
"la victoria lograda por el heroico pueblo vietnamita ... en treinta años de guerra ... nos enseña que existe un cuarto pilar necesario para el triunfo de la revolución: la solidaridad internacional ... con la que el campo socialista y los pueblos amantes de la paz y de la democracia, rodearon la gesta liberadora de Vietnam ... nos deja algunas enseñanzas más ... es necesaria en la época de ... reflujo de las masas " (1978: 4-5).
}

\footnotetext{
también era interpelada por esta situación. En efecto, sostiene Casola que, para el PCA "la política exterior de los Estados Unidos centrada en los derechos humanos era denunciada como una campaña de injerencia del imperialismo .... estaba fundamentalmente dirigida a denunciar las graves denuncias que recaían sobre la Unión Soviética. Sin embargo para que fuese creíble ... debió incluir y mostrar preocupación por la situación de los derechos humanos en los países de su área de influencia" (2012: 1-2). Como veremos pueden detectarse en este aspecto, notables coincidencias en las lecturas del PRT y del PCA. Asimismo, suponía no registrar los matices en la opinión pública norteamericana y su capacidad de influencia en la política exterior de su país, que destaca Morello (2012) con el rol del catolicismo "cívico".
} 


\title{
Leandro Inchauspe
}

Aparecía como clave, entonces, romper esa política contemplativa con la dictadura que en el plano internacional llevaba adelante el campo socialista.

Para sortear esta contradicción, el documento recurría, paradójicamente, a las definiciones del Movimiento Comunista Internacional, liderado por la URSS, que a fines de los sesenta había definido a la solidaridad internacional como "la unión de la comunidad socialista, la clase obrera y las fuerzas democráticas de los países capitalistas, los pueblos liberados y los pueblos oprimidos” (1978: 8) ¿cómo lograrlo? la respuesta significaba una gran ampliación del esquema de alianzas que históricamente venía sosteniendo el partido:

\footnotetext{
"el trabajo en todos los organismos de masas ... las agrupaciones profesionales o sectoriales ... los organismos humanitarios ... comunistas ... socialdemócratas o apolíticos, cristianos o de otras religiones ... los organismos superestructurales ... los gobiernos" (1978: 9).
}

Una política tan amplia, que probablemente era novedosa para una militancia, formada en otras prácticas, era ejemplificada apelando a distintas formas de ligar la lucha antidictatorial argentina con luchas nacionales en distintos países:

\begin{abstract}
"Con los pueblos democráticos nos une la defensa de la democracia. Es el caso de Venezuela, que hace veinte años derrotó con una formidable movilización la dictadura de Pérez Jiménez ... En el caso de los Estados Unidos ... debemos apoyarnos en la vocación democrática de su pueblo ... en cuanto al gobierno [de EEUU] ... buscando los elementos más liberales de su equipo gobernante ... Con los pueblos y gobiernos progresistas, nos une la lucha contra el imperialismo" (1978: 10-11).
\end{abstract}

Se continuaba mencionando a los países europeos y su lucha contra el fascismo en la Segunda Guerra Mundial (y en la guerra civil en el caso español) y la tradición de la gran "revolución democrática-burguesa" para Francia, entre otros. También se mencionaba, además de pueblos y gobiernos en particular, a organizaciones supranacionales como las "las iglesias de todas las confesiones, se unen en la defensa de los derechos humanos, demostrar su violación masiva será lo determinante de nuestra tarea con ellas" (1978: 11).

Si esta particularización podía ser pensada como una dificultad, el documento planteaba que existía una forma de articulación, señalada en las conclusiones: "la tarea de los revolucionarios ... sobre lo que ocurre en nuestro país, convencer de que nuestro enemigo, es el enemigo de la humanidad" (1978: 14). Síntesis de la tarea estratégica de "enmarque" de sus temas, según Keck y Sikkink, para traducirlos de manera sencilla, en términos de bien y mal, para persuadir en que la dictadura argentina se oponía, nada menos, que a la humanidad entera.

En otro documento que presumimos fue elaborado por el sector de Mattini (que, según Carnovale, conservó la denominación partidaria) hacia 1980, se definían los "Objetivos y tareas para la etapa" a partir de una historización de la actividad 


\title{
"El Cuarto Pilar de la Revolución": del internacionalismo proletario a la solidaridad internacional, las transformaciones discursivas del Partido Revolucionario de los Trabajadores en el exilio
}

partidaria ya redefinida como sostenida en "la tesis de los cuatro pilares ... Partido Revolucionario ... Ejército Popular ... Frente de Liberación Nacional y ... solidaridad internacional" (Objetivos y tareas para la etapa, 1980, El Topo Blindado. Centro de Documentación de las organizaciones político militares argentinas, pp. 3) ${ }^{14}$. Párrafos más abajo se observa que, aún sin dejar de lado la lucha armada, las tareas se definían en términos menos "militaristas" que los que venían siendo habituales hasta el inicio del exilio: "debemos combinar ... el trabajo legal con el ilegal, violentos y pacíficos, armados y no armados ... la lucha política, la lucha económica y la lucha armada" (1980: 6). En las consignas concretas que expresaban estas luchas se mencionaban libertades políticas, sindicales, vigencia de los DDHH, fin del "terrorismo de estado", "aparición con vida de los detenidos-desaparecidos", libertad a los presos políticos y reivindicaciones salariales. No había consignas explícitamente socialistas, ni antiimperialistas ni anticapitalistas. En forma muy clara, se decía luego que "la actividad militar ... deberá tener un profundo contenido político" (1980: 9). El carácter transicional de este documento queda en evidencia en esta preocupación por resaltar el carácter político de la etapa, por sobre el estrictamente militar. El "enmarque", nuevamente puede ser pensado para explicar estos giros: el público internacional al que se interpelaba podía ser pensado como menos receptivo hacia el predominio de la estrategia de la lucha armada.

Volviendo a nuestro interés principal, en un apartado titulado "Internacional" se sostiene el "carácter estratégico" del "cuarto pilar" mostrándose la reciente orientación hacia la aceptación del "campo socialista" liderado por la URSS que ya hemos señalado, en combinación con las anteriores apelaciones latinoamericanistas y militares, de cuño guevarista. En efecto, se sostenía que la política internacional de la organización

\begin{abstract}
"buscará tres objetivos: 1- El reconocimiento y el apoyo político y práctico del campo socialista. 2- el aislamiento de la dictadura por parte de los ... gobiernos no socialistas ... 3- ... coordinación con las organizaciones revolucionarias de nuestro continente, en vistas al desarrollo continental de nuestra guerra" (circa 1980: 9).
\end{abstract}

Inmediatamente después se definía a la solidaridad internacional como la tarea de "explicar a los pueblos y gobiernos amantes de la paz y la democracia, la situación concreta por la que atraviesa la lucha de resistencia de nuestro pueblo" y la concepción aún de inspiración vietnamita de la misma: "para que de esta manera se constituya en una verdadera retaguardia del frente de lucha que es nuestro país". La ampliación del público destinatario al que se apelaba, en términos de RTD, nuevamente es posible de ser señalado en esta estrategia que intenta superar

\footnotetext{
${ }^{14}$ Recuperado en: http://eltopoblindado.com/opm-marxistas/partido-revolucionario-de-lostrabajadores-prt/prt-exilio/objetivos-y-tareas-para-la-etapa/
} 


\section{Leandro Inchauspe}

divisiones que previas a la dictadura fueron claves, casi identitariamente constitutivas.

Otro documento de interés para seguir observando cómo se reelaboran los posicionamientos de la organización en lo internacional se titulaba "Situación política mundial", fechada a inicios de 1982 y realizaba su análisis dividiendo en forma clásica el campo imperialista, el socialista y "la periferia". Sobre estos dos últimos fijamos la atención.

En relación al campo socialista, se hace mención a una crisis económica mundial que lo estaba afectando, con particular intensidad en Polonia, en la cual produjo una crisis también de tipo política. A raíz de esta situación, el documento perretiano reconocía que "existen diferencias al interior del campo socialista en varias concepciones de los grandes temas de la construcción del Socialismo" "Situación política mundial", 1982: 3) ${ }^{15}$ que establecían matices entre "Europa del Este" y "los países que pertenecieron a la periferia del capitalismo y lograron iniciar la construcción del Socialismo (África, Asia, A. Latina)”. Según el análisis, eran tres las cuestiones en las que se concentraban las diferencias aludidas: "el proyecto, la forma de construcción del socialismo ... la relación entre el Partido y las masas ... la concepción de la democracia obrera" (1982: 4). Es interesante destacar que en esta contraposición de bloques de países respecto a temas tan claves, se evidencia una mayor valoración "tercermundista", de resonancia guevarista, respecto a las experiencias en Europa Oriental: "es en la periferia donde se llevan adelante los procesos más interesantes, más pujantes y qué más cercanos a nosotros se hallan: Vietnam ... Angola y Mozambique ... Cuba, Nicaragua y Granada” (1982: 4). Por otra parte, se percibe en el análisis un intento de legitimar en las experiencias concretas, estos acercamientos que el PRT estaba realizando hacia las posiciones de la izquierda tradicional. Por un lado, señalando como desde el campo liderado por la URSS "la política de los países socialistas hacia el movimiento revolucionario y de liberación se mantiene en una tendencia al estrechamiento de vínculos” (1982: 5). Por otra parte, marcando una línea similar desde la izquierda revolucionaria en América Latina: "tendencia unitaria entre la izquierda revolucionaria y la tradicional (PC) El Movimiento Revolucionario se mantiene en un avance ... reafirmando la tendencia a la unidad de este y los PC's y otros sectores populares" (1982: 6). Si bien no nos encontramos en condiciones de medir cuánto de esta afirmación puede ser respaldada empíricamente y cuánto respondía a una expresión de deseos de la organización, interesa subrayar esta tendencia a minimizar la complejidad de la relación que habían mantenido a lo largo de los años previos. Tendencia que coincide con las lógicas de las RTD que necesitan ampliar sus públicos.

\footnotetext{
${ }^{15}$ Recuperado en: http://eltopoblindado.com/opm-marxistas/partido-revolucionario-de-lostrabajadores-prt/prt-exilio/situacion-politica-mundial/
} 


\section{"El Cuarto Pilar de la Revolución": del internacionalismo proletario a la solidaridad internacional, las transformaciones discursivas del Partido Revolucionario de los Trabajadores en el exilio}

Cerramos este recorrido con los dos números del "Boletín de la Secretaría Internacional del PRT-ERP”16. El número uno fue publicado en junio de $1980^{17}$ y se abre con un extenso artículo titulado "Argentina: situación del movimiento obrero", de las páginas 2 a 7, con numerosos datos históricos, económicos sociales, de su estructura sindical, sobre los efectos de la represión y con las perspectivas que se anunciaban de reactivación del activismo obrero. Le sigue luego una nota sobre la lucha guerrillera en El Salvador; un comunicado de un "Comité Nicaragüense de Solidaridad con los Pueblos" que repudia 'las maniobras imperialistas' en Centroamérica y el Caribe; y una nota en conmemoración del Cordobazo.

Por su parte, el Boletín número dos ${ }^{18}$ publicado al mes siguiente, se iniciaba con una nota sobre el triunfo del sandinista en Nicaragua, llamativamente firmada por Gorriarán Merlo - recordemos que, tras el cisma partidario, siguiendo a Carnovale, este dirigente lideraba la facción contraria a la que conservaba el nombre partidario y se encontraba luchando en el país centroamericano-19. Luego le seguían una serie de notas sobre la situación argentina: declaraciones de dirigentes partidarios peronistas, radicales, intransigentes y de otras expresiones; otra sobre conflictos sindicales en diversos sectores; una en conmemoración de la caída en combate de Santucho; una carta de presos políticos a los obispos argentinos; una nota del diario "Buenos Aires Herald" sobre la situación de los desaparecidos y efemérides de diversas luchas populares de nuestro país. Las dos últimas notas referían a la situación, nuevamente, de la lucha guerrillera en El Salvador y las acciones para la unificación de Corea.

\footnotetext{
${ }^{16}$ La producción de la organización en esta etapa excede ampliamente lo aquí trabajado. Numerosos boletines internos centrados en, o con referencia a, las tareas de solidaridad internacional del partido, o con su apoyo; volantes, folletines y otros documentos sobre acciones con organismo de solidaridad argentinos - CADHU, COSOFAM, "Trabajadores y Sindicalistas Argentinos en el Exilio TYSAE", Comisión de Familiares de Víctimas de la Represión en Argentina, Campaña contra el Mundial 78, Campaña por la libertad de Piccinini - publicaciones periódicas como "Denuncia", "Argentina Hoy, "Boletín Argentina". Esta profusa producción da cuenta de una gran tarea militante en el exilio, de la cual este trabajo constituye una aproximación. Y si bien no constituye el objeto central de nuestro interés, tarea que se realizó en convergencia con numerosos grupos de exiliados/as y de un amplio espectro ideológico en los países de acogida, dando cuenta del aspecto de "red de relaciones" que caracteriza a las RTD. Sin embargo, no estamos en condiciones de dar cuenta sobre la existencia de redes de solidaridad internacional fuera de América Latina, en Europa Occidental, de las hay referencia en alguna literatura testimonial, y en el campo socialista, respecto al cual existen escasas menciones. Agradecemos las observaciones realizadas en el referato, en este sentido, aun cuando su respuesta está fuera de nuestros objetivos.

${ }^{17}$ Recuperado en: http://eltopoblindado.com/opm-marxistas/partido-revolucionario-de-lostrabajadores-prt/boletin-secretaria-internacional-n-1/

${ }^{18}$ Recuperado en: http://eltopoblindado.com/opm-marxistas/partido-revolucionario-de-lostrabajadores-prt/boletin-secretaria-internacional-n-2/

${ }^{19}$ La sorpresa aumenta avanzando en la nota: una reivindicación de la lucha armada, combinada, eso sí, con la política, a partir de la victoria sandinista. Y una condena a quienes "abandonan el camino revolucionario" al abjurar a la estrategia guerrillera, cuyo destinatario podría ser el sector de Mattini...es probable que las fronteras marcadas luego del cisma de 1979 hayan sido extremadamente lábiles, así como que las características de la dispersión en diversos países hayan dificultado la centralización y control de las publicaciones partidarias por parte de la Dirección.
} 


\section{Leandro Inchauspe}

Puede percibirse una fuerte presencia de las luchas latinoamericanas (en particular, las guerrillas en Nicaragua y El Salvador) y escasa presencia de otras regiones (el campo socialista, los gobiernos surgidos de los movimientos de liberación nacional), quizás atribuible a que los contactos partidarios se reducían a las guerrillas centroamericanas. Como podía esperarse de una publicación internacional de una organización argentina, la mayor parte de su producción refería a nuestro país. En la cual puede verse una combinación de referencias que formaron parte del repertorio del partido en su etapa previa (las luchas del movimiento obrero, la conmemoración de los mártires partidarios) y la novedad de las denuncias a las violaciones a los DDHH realizados por la dictadura. Como puede comprenderse; por una parte, no puede pensarse que sea posible una homologación total entre la discursividad del PRT en el exilio y las características de las RTD. Y por otra parte, las tareas de "enmarque" para adecuar los discursos a los nuevos públicos internacionales se realizan en y desde las tradiciones previas, lo que se refleja en las mixturas.

\section{Conclusiones}

A partir de lo relevado estamos en condiciones de afirmar la existencia de un itinerario, en el plano de las posiciones públicas y de las destinadas a la propia militancia, desde el trotskismo inicial hacia un comunismo más cercano a Moscú, pasando por el guevarismo que funciona tanto como facilitador de la salida de la tradición de la IV Internacional en los primeros años, como de tracción hacia posiciones más latinoamericanistas y de continuidad de la reivindicación de lo militar, en la etapa del exilio.

En efecto, en los inicios mostramos como en los dos afluentes que constituyeron el partido la dimensión internacional era considerada constitutiva, sea en clave indoamericana o en la clásica marxista del internacionalismo proletario. De características más declarativas que prácticas en la experiencia del FRIP, toda vez que las acciones que conocemos se redujeron a declaraciones de solidaridad con alguna situación de represión; con un componente también práctico en el caso de PO que realizó además acciones y formación militar en países latinoamericanos.

En el plano de los posicionamientos teóricos, observamos tanto las marcas del trotskismo, en su crítica a la trayectoria de la URSS a partir del liderazgo de Stalin, como las del guevarismo. Siempre con las secuencias de la lucha vietnamita como referencia: una etapa de guerra civil inicial, intervención militar imperialista luego, que derivaría en guerra patriótica antiimperialista en la etapa final. En ella, aunque en la práctica ejercida tenuemente en los momentos previos al golpe, la solidaridad internacional como cuarto pilar de la revolución aparece en el horizonte en el plano discursivo.

La práctica concreta del internacionalismo se realizará con la JCR, a la que coincidimos con Sujatt en considerar 'internacionalismo armado', de fuerte cuño guevarista. Intentó llevar a la práctica la propuesta de Guevara en su Mensaje a la 


\section{"El Cuarto Pilar de la Revolución": del internacionalismo proletario a la solidaridad internacional, las transformaciones discursivas del Partido Revolucionario de los Trabajadores en el exilio}

Tricontinental, articulando la operatividad militar de las guerrillas en Argentina, Bolivia, Chile y Uruguay - aun teniendo en cuenta las importantes diferencias entre las organizaciones que la formaban-. El tono es fuertemente latinoamericano, casi sin mención a la tradición revolucionaria clásica, con la sola excepción de Vietnam, que aparecía tanto en el horizonte del propio Che como en el imaginario perretista. El arrasamiento en vidas y estructuras que significó la dictadura llevó a que hacia 1977 la organización en Argentina quedase con una operatividad prácticamente nula. El camino del exilio fue el que permitió la continuidad de alguna práctica militante, al tiempo que exigió una fuerte readecuación de las estrategias. Como esperamos haber demostrado, esto no supuso insertar al partido en una Red Transnacional de Defensa en términos de Keck y Sikkink, pero sí que es posible aplicar parcialmente la categoría para arrojar luz sobre algunas transformaciones, en particular en las tareas de "enmarque" para conformar visiones del mundo y de sí tendientes a legitimar y motivar acciones colectivas internacionales de denuncia de la dictadura argentina.

Respecto a ese recorrido del partido en el exilio, coincidimos en parte con Carnovale en una progresiva orientación hacia el comunismo que reconocía el liderazgo de la URSS en el campo socialista, que significa un total abandono de su trotskismo inicial, realizado por el sector de Mattini que conservaría la denominación partidaria, pero entendida como parte de las tareas de enmarque. Itinerario que la adhesión al guevarismo, junto al peso de la experiencia vietnamita, ya había facilitado: el abandono de la IV Internacional fue realizado en 1973. Por eso sostenemos que es el guevarismo, con el agregado vietnamita, el que facilita la salida de la tradición de origen. Y también marca límites al momento de las redefiniciones del exilio y a las tareas de enmarque. La adhesión al Movimiento Comunista Internacional se hace desde un posicionamiento tercermundista, desde los movimientos de liberación nacional, lo que permitía la continuidad del latinoamericanismo y, más importante aún, de la corrección de la lucha armada. Por ello encontramos más efectos del enmarque que rupturas en la línea política. Argentina, sus luchas populares, sus líderes guerrilleros son principalmente evocados cuando el partido realiza sus boletines de distribución internacional; junto a las luchas guerrilleras que por entonces se intensificaban en Nicaragua y El Salvador. Es en esta perspectiva que el cuarto pilar debía funcionar como retaguardia de la lucha que se libraría - ya con características muy distintas a las del auge guerrillero de los años previos, por cierto- en nuestro país, para cubrirla de solidaridad internacional, con la del campo socialista pero también con la de las democracias capitalistas occidentales. Esta confluencia puede ser entendida en términos de RTD, en términos de enmarque para ampliar los públicos internacionales destinatarios.

Esta particular articulación de internacionalismo clásico, despojado ya de la crítica trotskista a la URSS, chocaba con un sólido inconveniente: la negativa de Moscú a condenar a la dictadura argentina por las violaciones a los DDHH. Un fracaso, 


\section{Leandro Inchauspe}

comprensible en cuanto a las tareas que se fijan las RTD de influir en las posiciones internacionales de los estados nacionales, dadas las particularidades que definían la política exterior soviética, pero también la de EE.UU. con la administración Carter. Y frente a eso, la experiencia del cuarto pilar de la revolución realizada por la lucha vietnamita vuelve a ser la referencia teórica. Y se postula una enorme ampliación de las articulaciones que tradicionalmente el PRT llevó adelante en sus experiencias previas, en una gran tarea estratégica de enmarque de sus tópicos y destinatarios. Vastos sectores políticos, religiosos, profesionales, gubernamentales son destinatarios de las denuncias a la dictadura buscando sumarlos a la solidaridad internacional con la resistencia antidictatorial. Y se lo realiza no en términos de socialismo y revolución si no con una apelación muchísimo más universalista: "convencer de que nuestro enemigo, es el enemigo de la humanidad". Un máximo esfuerzo persuasivo, simplificador, en términos de bien y mal, tal como lo requieren las tareas de enmarque.

Esta estrategia da cuenta del esfuerzo militante de la organización para articular en el plano internacional una peculiar combinación de guevarismo, latinoamericanismo, experiencia vietnamita, comunismo tradicional y humanismo que requiere mayores esfuerzos investigativos a futuro para verificar si pudo ser plasmado en prácticas concretas.

\section{Bibliografía}

Águila, G (2008) “El Partido Comunista Argentino entre la dictadura y la transición democrática (1976-1986)" Revista Historia Actual, Vol. 6, Núm. 6, 57-69.

Alonso, L (2017) "Terror de Estado y luchas pro derechos humanos en Argentina: las dimensiones ocluidas", Ayer, 107(3), pp. 99-124.

Carnovale, V. (2014) "El PRT-ERP en el exilio. Armas, comunismo y derechos humanos". Revista de Historia, 0(15), 1-28. Recuperado de http://revele.uncoma.edu.ar/htdoc/revele/index.php/historia/article/view/868

Casola, N. (2012) "El Partido Comunista de Argentina y el exilio en Europa durante la última dictadura militar: Caracterizaciones políticas, alianzas y disputas”. I Jornadas de Trabajo sobre Exilios Políticos del Cono Sur en el siglo XX, 26, 27 y 28 de septiembre de 2012, La Plata. Agendas, problemas y perspectivas conceptuales. En: Actas. La Plata: UNLP-FAHCE. Recuperado de: http://www.memoria.fahce.unlp.edu.ar/trab_eventos/ev.2533/ev.2533.pdf

De Santis, D (2000) A vencer o morir. PRT-ERP. Documentos, Tomo 2. Buenos Aires, Eudeba. 


\section{"El Cuarto Pilar de la Revolución": del internacionalismo proletario a la solidaridad internacional, las transformaciones discursivas del Partido Revolucionario de los Trabajadores en el exilio}

De Santis, D (2004) A vencer o morir. Historia del PRT-ERP. Documentos, Tomo I, volumen 1, Buenos Aires, Nuestra América.

De Santis, D (2004) A vencer o morir. Historia del PRT-ERP. Documentos, Tomo I, volumen 2, Buenos Aires, Nuestra América.

Inchauspe, L (2018) “Guerras por la paz. Tradiciones teóricas influyentes en las concepciones político militares del Partido Revolucionario de los TrabajadoresEjército Revolucionario del Pueblo (PRT-ERP)", Goicovic, I y Vasallo, J (Compiladores) América Latina. Violencias en la Historia, Valparaíso, Chile, América en Movimiento, pp. 137-160.

Keck, M y Sikkink, K (1999) "Las redes transnacionales de defensa en la política internacional y regionales", International Social Sciencie Journal, n¹59, UNESCO, pp. 89-101. Recuperado de http://www.unesco.org/issj/rics159/keckspa.html

Mangiantini, M (2018) Itinerarios militantes. Del Partido Revolucionario de los Trabajadores al Partido Socialista de los Trabajadores (1965-1976), Buenos Aires, Imago Mundi.

Marchesi, A. (2009) “Geografías de la protesta armada: Nueva izquierda y latinoamericanismo en el cono sur. El ejemplo de la Junta de Coordinación Revolucionaria", Sociohistórica (25), 41-72. Recuperado de: http://www.fuentesmemoria.fahce.unlp.edu.ar/art_revistas/pr.4431/pr.4431.pdf

Morello, G (2012) "Secularización y Derechos Humanos. Actores católicos entre la dictadura argentina (1976) y la administración Carter (1977-1979)", Latin American Research Review, vol 47, núm 3, pp. 61-82.

Sujatt, J. (2016). “La Junta de Coordinación Revolucionaria (1972- 1979). Una experiencia de internacionalismo armado en el Cono Sur de América Latina”, Cuadernos De Marte, $O(10), 107-145$.

Recibido: $15 / 01 / 2020$

Evaluado: $24 / 02 / 2020$

Versión Final: 25/03/2020 